\title{
Evaluasi Sistem Proteksi Aktif dan Pasif sebagai Upaya Penanggulangan Bahaya Kebakaran pada Gedung X Mall
}

\author{
Katarina Rini Ratnayanti, Nur Laeli Hajati, Mutiara Indah Rizki Utama \\ Jurusan Teknik Sipil, Fakultas Teknik Sipil dan Perencanaan, ITENAS, Bandung \\ Email:katrinr235@gmail.com eli10871@gmail.com mutiaraindah2995@gmail.com
}

\begin{abstract}
ABSTRAK
X Mall merupakan sebuah pusat perbelanjaan yang menyediakan berbagai fasilitas lengkap mulai dari pusat perbelanjaan, arena rekreasi, kawasan kuliner, bank, hingga tempat peribadatan. X Mall termasuk tingkat risiko bahaya kebakaran sedang III yang memiliki potensi pemicu kebakaran dari dalam dan luar gedung. Maka dari itu X Mall perlu menerapkan sistem proteksi kebakaran dan sarana pendukung yang baik untuk mencegah dan menanggulangi bahaya kebakaran. Penelitian ini dilakukan dengan cara observasi dan wawancara langsung dengan pihak X Mall untuk mengetahui kelengkapan dan kondisi sistem proteksi aktif, sistem proteksi pasif, serta manajemen kebakaran yang telah diterapkan. Hasil observasi dan wawancara kemudian dibandingkan kesesuaiannya dengan peraturan yang berlaku di Indonesia yaitu Kepmen PU No.10/KPTS/2000 dan SNI. Hasil penelitian menunjukan bahwa sistem proteksi aktif, sistem proteksi pasif, sarana penyelamatan jiwa, dan manajemen tanggap kebakaran sudah cukup baik dengan umumnya persentase kesesuaian $\geq 80 \%$.
\end{abstract}

Kata kunci: kebakaran, bahaya kebakaran, mall, proteksi aktif, proteksi pasif, manajemen kebakaran

\begin{abstract}
$X$ Mall is a shopping centre that provides complete facilities such as supermarket, recreation arena, culinary, bank, also place of worship. The level of risk of fire hazard in X Mall is classified as Moderate III Fire Hazard that has the potential fire triggering from inside and outside the building. Therefore $X$ Mall needs to implements fire protection system and good supporting facilities to prevent and overcome fire hazards. This research was done by observation and direct interviews with the X Mall to find out the availability and condition of active protection system, passive protection system, and fire management that have been implemented. The results of observation are then compared to the applicable regulations that are Kepmen PU No. 10/KPTS/2000 and SNI. The final results showed that active and passivefire protection system, lif saving facilities, and fire reponse management is quite good, with generally the percentage of suitability $\geq 80 \%$.
\end{abstract}

Keywords: fire, fire hazard, mall, active protection, passive protection, fire management 


\section{PENDAHULUAN}

Kebakaran merupakan bencana yang dapat terjadi di mana saja dan kapan saja yang umumnya ditimbulkan oleh kelalaian manusia yang mengakibatkan kerugian jiwa dan materi. Kebakaran dapat terjadi pada pusat perbelanjaan modern dilihat dari banyaknya potensi pemicu kebakaran seperti korsleting listrik, percikan api dari pantry atau rokok yang mengenai bahan-bahan yang cepat merambatkan api seperti kain, kertas, atau bahan bakar yang menetes di area parkir kendaraan. Pusat perbelanjaan modern memiliki area yang luas dan ramai dikunjungi berbagai kalangan dari mulai balita hingga lanjut usia menjadikan proses evakuasi sulit apabila terjadi kebakaran. Maka dari itu gedung pusat perbelanjaan modern harus dilengkapi dengan sistem proteksi aktif, sistem proteksi pasif, serta sarana penyelamatan jiwa yang baik sesuai peraturan yang berlaku untuk mencegah dan menanggulangi bahaya kebakaran pada gedung.

\subsection{Sistem Proteksi Aktif}

\section{TINJAUAN PUSTAKA}

Sistem proteksi aktif adalah sistem perlindungan terhadap kebakaran yang dilaksanakan dengan mempergunakan peralatan yang dapat bekerja secara otomatis maupun manual, digunakan oleh penghuni atau petugas pemadam kebakaran dalam melaksanakan operasi pemadaman [1].

\subsection{Sistem Proteksi Pasif}

Sistem proteksi pasif adalah sistem perlindungan terhadap kebakaran yang dilaksanakan dengan melakukan pengaturan terhadap komponen bangunan gedung dari aspek arsitektur dan struktur sedemikian rupa sehingga dapat melindungi penghuni dan benda dari kerusakan fisik saat terjadi kebakaran [1].

\subsection{Sarana Penyelamatan Jiwa}

Sarana penyelamatan adalah sarana yang dipersiapkan untuk dipergunakan oleh penghuni maupun petugas pemadam kebakaran dalam upaya penyelamatan jiwa manusia maupun harta-benda bila terjadi kebakaran pada suatu bangunan gedung dan lingkungan [1].

\subsection{Manajemen Proteksi Kebakaran pada Bangunan Gedung}

Pengelola gedung harus memiliki Manajemen Proteksi Kebakaran agar fasilitas proteksi kebakaran yang tersedia dalam gedung dimanfaatkan dengan baik. Fire Safety Management (FSM) adalah kegiatan pemeriksaan berkala perawatan dan pemeliharaan, audit keselamatan kebakaran dan latihan penanggulangan kebakaran harus dilaksanakan secara periodik sebagai bagian dari kegiatan pemeliharaan sistem proteksi yang ada dan terpasang pada bangunan [1].

\subsection{Peraturan yang Digunakan}

Peraturan yang digunakan pada penelitian ini adalah Kepmen PU No. 10/KPTS/2000 [1], KepMenNaKer No. 186 Tahun 1999 [2], SNI 03-3985-2000 [3], SNI 03-3989-2000 [4], SNI 03-1745-2000 [5], SNI 03-1736-2000 [6], SNI 03-1746-2000 [7] dan SNI 03-6574-2001 [8].

\subsection{Penelitian Terdahulu}

Penelitian terdahulu mengenai penelitian kebakaran pada mall atau perbelanjaan dapat dilihat pada Tabel 1 berikut. 
Tabel 1. Daftar Penelitian Terdahulu

\begin{tabular}{cllll}
\hline No. & \multicolumn{1}{c}{$\begin{array}{c}\text { Peneliti } \\
\text { (tahun) }\end{array}$} & \multicolumn{1}{c}{ Judul Penelitian } & $\begin{array}{c}\text { Jenis } \\
\text { Penelitian }\end{array}$ & \multicolumn{1}{c}{ Hasil Penelitian } \\
\hline 1 & Muhammad & Analisis Struktur & Kualitatif & Konstruksi tangga darurat sebelah \\
& Septian Hadi, & Bangunan yang Ditinjau & & $\begin{array}{l}\text { barat, timur, dan selatan sudah sesuai } \\
\text { standar Kepmen PU No. 10 tahun }\end{array}$ \\
& Baju & dari Tangga & & 2000, kemiringan anak tangga terlalu \\
& Widjasena, & Darurat pada Pusat & & curam dan tidak sesuai dengan \\
& Suroto & Perbelanjaan Mesra Indah & & standar, dan lebar tangga tidak sesuai \\
& $(2015)$ & Mall Samarinda & & dengan standar \\
\hline [9] & Kurniati & Kajian tentang Penerapan & Deskriptif & Kondisi bangunan pusat perbelanjaan \\
& Ornam & Sistem Keselamatan Jiwa & & Mal Mandonga Kendari termasuk \\
& $(2011)$ & Terhadap Bahaya & & dalam kategori tidak aman terhadap \\
& {$[\mathbf{1 0}]$} & Kebakaran pada & & bahaya kebakaran karena kurangnya \\
& & Perancangan Pusat & sarana dan prasarana proteksi \\
& Perbelanjaan & & \\
& Mal Mandonga Kendari & & \\
& & &
\end{tabular}

\section{METODOLOGI PENELITIAN}

Penelitian ini dimulai dengan mengidentifikasi dan merumuskan masalah kemudian melakukan studi literatur sebagai referensi seperti peraturan dan penelitian terdahulu tentang masalah terkait yaitu mengenai gedung, pusat perbelanjaan, dan kebakaran. Sebelum melakukan pengumpulan data terlebih dahulu dibuat perancangan alat ukur penelitian yang berisi tentang apa saja parameter yang diperlukan untuk penelitian agar observasi dan wawancara relevan dengan masalah yang akan diteliti.

Dari perancangan ukur tersebut diketahui bahwa data yang dibutuhkan meliputi denah alat pemadam kebakaran yang terpasang pada gedung dan luas bangunan gedung yang akan diteliti, jenis alat, jumlah alat, kondisi alat, manajemen pemadam kebakaran yang diterapkan pada gedung, proteksi pasif yang tersedia, serta peraturan terkait yang berhubungan dengan sistem proteksi kebakaran pada gedung. Pengumpulan data dilakukan dengan cara melakukan observasi lapangan pada objek yang akan diteliti dan wawancara langsung dengan pihak pengelola gedung. Data yang didapatkan berupa data primer dan sekunder.

Pengolahan data dilakukan dengan cara melakukan perhitungan kebutuhan alat pemadam kebakaran pada gedung X Mall yang mengacu pada peraturan yang berlaku dengan cara membagi luasan lantai dengan kapasitas layan dari alat. Setelah mendapatkan hasil dari pengolahan data, kemudian dilakukan analisis gap. Analisis ini dilakukan dengan cara membandingkan kesenjangan kondisi dan ketersediaan alat yang terpasang pada gedung mulai dari kesesuaian jumlah alat pemadam yang harus terpasang, kondisi proteksi aktif, kondisi proteksi pasif, serta sarana penyelamatan jiwa dengan peraturan yang berlaku. Dari hasil analisis yang didapatkan maka dapat ditarik kesimpulan, saran, dan rekomendasi bagi gedung yang diteliti. 


\section{HASIL PENELITIAN DAN ANALISIS}

Beradasarkan peraturan [2], X Mall termasuk tingkat risiko bahaya kebakaran sedang III yang memiliki potensi pemicu kebakaran dari dalam dan luar gedung. Analisis pada penelitian ini adalah analisis gap yaitu membandingkan kesenjangan kondisi dan jumlah sistem proteksi kebakaran yang terpasang pada X Mall dengan peraturan yang berlaku.

\subsection{Sistem Proteksi Aktif}

Sistem proteksi aktif kebakaran meliputi alarm kebakaran, APAR, detektor, hydrant, dan sprinkler.

\subsubsection{Alarm Kebakaran}

Peraturan yang digunakan dalam analisis gap alarm kebakaran ini adalah [1] dan [3]. Analisis kondisi alarm kebakaran dapat dilihat pada Tabel 2 berikut.

Tabel 2. Hasil Analisis Kondisi Alarm Kebakaran pada X Mall

\begin{tabular}{|c|c|c|c|c|c|c|c|}
\hline No. & $\begin{array}{l}\text { Kondisi } \\
\text { Existing }\end{array}$ & $\sum$ & $\begin{array}{c}\text { Kondisi } \\
\text { yang } \\
\text { Diharapkan }\end{array}$ & $\sum$ & Gap & $\begin{array}{l}\text { Persentase } \\
\text { Kesesuaian }\end{array}$ & Rekomendasi \\
\hline \multirow[t]{10}{*}{1} & $\begin{array}{l}\text { Jumlah alarm } \\
\text { kebakaran } \\
\text { terpasang } \\
\text { pada gedung: }\end{array}$ & & $\begin{array}{l}\text { Jumlah alarm } \\
\text { kebakaran yang } \\
\text { dibutuhkan: }\end{array}$ & & & & \\
\hline & Lantai SB & 6 & Lantai SB & 10 & -4 & $60 \%$ & Menambah 4 unit alat \\
\hline & Lantai LG & 10 & Lantai LG & 10 & 0 & $100 \%$ & - \\
\hline & Lantai GF & 6 & Lantai GF & 10 & -4 & $60 \%$ & Menambah 4 unit alat \\
\hline & Lantai FF & 6 & Lantai FF & 10 & -4 & $60 \%$ & Menambah 4 unit alat \\
\hline & Lantai P1 & 8 & Lantai P1 & 10 & -2 & $80 \%$ & Menambah 2 unit alat \\
\hline & Lantai P2 & 8 & Lantai P2 & 1 & +7 & $100 \%$ & - \\
\hline & Lantai 4 & 1 & Lantai 4 & 1 & 0 & $100 \%$ & - \\
\hline & Lantai 5 & 1 & Lantai 5 & 1 & 0 & $100 \%$ & - \\
\hline & Lantai 6 & 1 & Lantai 6 & 1 & 0 & $100 \%$ & - \\
\hline 2 & $\begin{array}{l}\text { Terdapat alarm } \\
\text { manual dan } \\
\text { otomatis } \\
\text { di gedung yang } \\
\text { terhubung } \\
\text { dengan MCFA }\end{array}$ & & $\begin{array}{l}\text { Alarm kebakaran } \\
\text { harus mencakup } \\
\text { alarm manual dan } \\
\text { otomatis. }\end{array}$ & & - & $100 \%$ & $\begin{array}{l}\text { Kondisi sesuai, tetapi } \\
\text { harus tetap dilakukan } \\
\text { pemeriksaan dan } \\
\text { pemeliharaan rutin agar } \\
\text { alat tetap berfungsi dengan } \\
\text { baik }\end{array}$ \\
\hline 3 & $\begin{array}{l}\text { Jarak antar alarm } \\
35 \text { m sampai } 45 \\
\text { m }\end{array}$ & & $\begin{array}{l}\text { Jarak antar alarm } \\
\text { maksimal } 30 \mathrm{~m}\end{array}$ & & $\begin{array}{l}\text { Partial } \\
\text { Gap }\end{array}$ & $70 \%$ & $\begin{array}{l}\text { Menambah jumlah alarm } \\
\text { sesuai yang dibutuhkan } \\
\text { dan melakukan pengaturan } \\
\text { tata letak ulang agar alarm } \\
\text { kebakaran tidak terlalu } \\
\text { berjauhan }\end{array}$ \\
\hline 4 & $\begin{array}{l}\text { Bunyi dan irama } \\
\text { alarm kebakaran } \\
\text { mudah dikenali }\end{array}$ & & $\begin{array}{l}\text { Mempunyai } \\
\text { bunyi serta irama } \\
\text { khas }\end{array}$ & & - & $100 \%$ & $\begin{array}{l}\text { Kondisi sesuai, tetapi } \\
\text { harus dilakukan sosialisasi } \\
\text { terhadap pengunjung agar } \\
\text { mengenali bunyi tanda } \\
\text { terjadinya kebakaran }\end{array}$ \\
\hline 5 & $\begin{array}{l}\text { Titik Panggil } \\
\text { Manual (TPM) } \\
\text { terletak } 1,3 \mathrm{~m}\end{array}$ & & $\begin{array}{l}\text { TPM terletak } \\
\text { maksimal } 1,4 \mathrm{~m} \\
\text { di atas }\end{array}$ & & - & $100 \%$ & $\begin{array}{l}\text { Kondisi sesuai, tetapi } \\
\text { harus tetap dilakukan } \\
\text { pemeriksaan dan }\end{array}$ \\
\hline
\end{tabular}



pada Gedung X Mall

\begin{tabular}{|c|c|c|c|c|c|c|c|}
\hline No. & $\begin{array}{l}\text { Kondisi } \\
\text { Existing }\end{array}$ & $\sum$ & $\begin{array}{c}\text { Kondisi } \\
\text { yang } \\
\text { Diharapkan }\end{array}$ & $\sum$ & Gap & $\begin{array}{l}\text { Persentase } \\
\text { Kesesuaian }\end{array}$ & Rekomendasi \\
\hline & $\begin{array}{l}\text { di atas } \\
\text { permukaan } \\
\text { lantai }\end{array}$ & & permukaan lantai & & & & $\begin{array}{l}\text { pemeliharaan rutin agar } \\
\text { alat tetap berfungsi dengan } \\
\text { baik }\end{array}$ \\
\hline 6 & $\begin{array}{l}\text { Terpasang TPM } \\
\text { pada masing- } \\
\text { masing lantai }\end{array}$ & & $\begin{array}{l}\text { TPM terpasang } \\
\text { pada setiap lantai }\end{array}$ & & - & $100 \%$ & $\begin{array}{l}\text { Kondisi sesuai, tetapi } \\
\text { harus dilakukan sosialisasi } \\
\text { agar penghuni gedung } \\
\text { mengetahui cara } \\
\text { penggunaan alat tersebut }\end{array}$ \\
\hline & $\begin{array}{l}\text { PERSENTASE } \\
\text { RATA }\end{array}$ & & JAIAN RATA- & & $92,4 \%$ & & \\
\hline
\end{tabular}

Berdasarkan Tabel 2 dapat diketahui bahwa persentase kesesuaian alarm kebakaran yang terpasang pada gedung adalah $92,4 \%$ sesuai.

\subsubsection{Detektor Panas}

Peraturan yang digunakan dalam analisis gap detektor panas ini adalah [1]. Analisis kondisi detektor panas dapat dilihat pada Tabel 3 berikut:

Tabel 3. Hasil Analisis Kondisi Detektor Panas pada X Mall

\begin{tabular}{|c|c|c|c|c|c|c|c|}
\hline No. & Kondisi Existing & $\sum$ & $\begin{array}{c}\text { Kondisi } \\
\text { yang } \\
\text { Diharapkan }\end{array}$ & $\sum$ & Gap & $\begin{array}{l}\text { Persentase } \\
\text { Kesesuaian }\end{array}$ & Rekomendasi \\
\hline \multirow[t]{3}{*}{1} & $\begin{array}{l}\text { Jumlah detektor } \\
\text { panas terpasang } \\
\text { pada gedung: }\end{array}$ & & $\begin{array}{l}\text { Jumlah detektor } \\
\text { panas yang } \\
\text { dibutuhkan: }\end{array}$ & & & & \\
\hline & Lantai SB & 154 & Lantai SB & 181 & -27 & $84 \%$ & $\begin{array}{l}\text { Menambah } 27 \text { unit alat } \\
\text { serta pengaturan tata } \\
\text { letaknya }\end{array}$ \\
\hline & Lantai LG & 390 & Lantai LG & 181 & +209 & $100 \%$ & - \\
\hline
\end{tabular}

Tabel 3. Hasil Analisis Kondisi Detektor Panas pada X Mall (lanjutan)

\begin{tabular}{|c|c|c|c|c|c|c|c|}
\hline No. & Kondisi Existing & $\sum$ & $\begin{array}{l}\text { Kondisi yang } \\
\text { Diharapkan }\end{array}$ & $\sum$ & Gap & $\begin{array}{l}\text { Persentase } \\
\text { Kesesuaian }\end{array}$ & Rekomendasi \\
\hline & Lantai GF & 466 & Lantai GF & 181 & +285 & $100 \%$ & - \\
\hline & Lantai FF & 317 & Lantai FF & 181 & +136 & $100 \%$ & - \\
\hline & Lantai P1 & 160 & Lantai P1 & 181 & -21 & $88 \%$ & $\begin{array}{l}\text { Menambah } 21 \text { unit alat } \\
\text { serta pengaturan tata } \\
\text { letaknya }\end{array}$ \\
\hline & Lantai P2 & 31 & Lantai P2 & 14 & +17 & $100 \%$ & - \\
\hline & Lantai 4 & 21 & Lantai 4 & 14 & +7 & $100 \%$ & - \\
\hline & Lantai 5 & 21 & Lantai 5 & 14 & +7 & $100 \%$ & - \\
\hline & Lantai 6 & 21 & Lantai 6 & 14 & +7 & $100 \%$ & - \\
\hline \multicolumn{6}{|c|}{ PERSENTASE KESESUAIAN RATA-RATA } & $96,8 \%$ & \\
\hline
\end{tabular}

Berdasarkan Tabel 3 dapat diketahui bahwa persentase kesesuaian detektor panas yang terpasang pada gedung adalah $96,8 \%$ sesuai. 


\subsubsection{Sprinkler}

Peraturan yang digunakan dalam analisis gap sprinkler ini adalah [1] dan [4]. Analisis kondisi sprinkler dapat dilihat pada Tabel 4 berikut:

Tabel 4. Hasil Analisis Kondisi Sprinkler pada X Mall

\begin{tabular}{|c|c|c|c|c|c|c|c|}
\hline $\begin{array}{l}\text { No } \\
\text {. }\end{array}$ & $\begin{array}{l}\text { Kondisi } \\
\text { Existing }\end{array}$ & $\sum$ & $\begin{array}{l}\text { Kondisi yang } \\
\text { Diharapkan }\end{array}$ & $\sum$ & Gap & $\begin{array}{c}\text { Persentase } \\
\text { Kesesuaia } \\
\text { n }\end{array}$ & Rekomendasi \\
\hline \multirow[t]{10}{*}{1} & $\begin{array}{l}\text { Jumlah } \\
\text { sprinkler } \\
\text { terpasang pada } \\
\text { gedung: }\end{array}$ & & $\begin{array}{l}\text { Jumlah sprinkler } \\
\text { yang dibutuhkan: }\end{array}$ & & & & \\
\hline & Lantai SB & 570 & Lantai SB & $\begin{array}{c}61 \\
3\end{array}$ & -43 & $93 \%$ & $\begin{array}{l}\text { Menambah } 43 \text { unit alat serta } \\
\text { pengaturan tata letaknya }\end{array}$ \\
\hline & Lantai LG & 583 & Lantai LG & $\begin{array}{c}64 \\
9\end{array}$ & -66 & $90 \%$ & $\begin{array}{l}\text { Menambah } 66 \text { unit alat serta } \\
\text { pengaturan tata letaknya }\end{array}$ \\
\hline & Lantai GF & 708 & Lantai GF & $\begin{array}{c}57 \\
3\end{array}$ & +135 & $100 \%$ & - \\
\hline & Lantai FF & 621 & Lantai FF & $\begin{array}{c}65 \\
0\end{array}$ & -29 & $95 \%$ & $\begin{array}{l}\text { Menambah } 29 \text { unit alat serta } \\
\text { pengaturan tata letaknya }\end{array}$ \\
\hline & Lantai P1 & 733 & Lantai P1 & $\begin{array}{c}65 \\
8\end{array}$ & +75 & $100 \%$ & - \\
\hline & Lantai P2 & 65 & Lantai P2 & 51 & +14 & $100 \%$ & - \\
\hline & Lantai 4 & 51 & Lantai 4 & 51 & 0 & $100 \%$ & - \\
\hline & Lantai 5 & 51 & Lantai 5 & 51 & 0 & $100 \%$ & - \\
\hline & Lantai 6 & 40 & Lantai 6 & 51 & -11 & $100 \%$ & $\begin{array}{l}\text { Menambah } 11 \text { unit alat serta } \\
\text { pengaturan tata letaknya }\end{array}$ \\
\hline 2 & $\begin{array}{l}\text { Tidak terdapat } \\
\text { sprinkler pada } \\
\text { panel listrik, } \\
\text { toilet, dan } \\
\text { tangga }\end{array}$ & & $\begin{array}{l}\text { Sprinkler tidak } \\
\text { dipasang pada } \\
\text { ruang tahan api, } \\
\text { kamar kakus, } \\
\text { ruang panel } \\
\text { listrik, dan tangga }\end{array}$ & & - & $100 \%$ & - \\
\hline 3 & $\begin{array}{l}\text { Jarak antar } \\
\text { sprinkler } 3 \mathrm{~m} \\
\text { sampai 4,3 m }\end{array}$ & & $\begin{array}{l}\text { Jarak antar } \\
\text { sprinkler } 2 \mathrm{~m} \\
\text { sampai } 4,6 \mathrm{~m}\end{array}$ & & - & $100 \%$ & $\begin{array}{l}\text { Kondisi sesuai, tetapi harus } \\
\text { tetap dilakukan pemeriksaan } \\
\text { dan pemeliharaan rutin agar } \\
\text { alat tetap berfungsi dengan } \\
\text { baik }\end{array}$ \\
\hline 4 & $\begin{array}{l}\text { Kapasitas } \\
\text { tangki air } 450 \\
\mathrm{~m}^{3}\end{array}$ & & $\begin{array}{l}\text { Kapasitas tangki } \\
\text { air minimum } \\
\text { untuk tinggi } \\
\text { bangunan }> \\
30 \mathrm{~m} \text { adalah } \\
185 \mathrm{~m}^{3}\end{array}$ & & - & $100 \%$ & $\begin{array}{l}\text { Kondisi sesuai, tetapi harus } \\
\text { tetap dilakukan pemeriksaan } \\
\text { dan pemeliharaan rutin agar } \\
\text { tangki tetap berfungsi } \\
\text { dengan baik }\end{array}$ \\
\hline & PERSEN & & SESUAIAN RAT & & & $99,4 \%$ & \\
\hline
\end{tabular}

Berdasarkan Tabel 4 dapat diketahui bahwa persentase kesesuaian spinkler yang terpasang pada gedung adalah $99,4 \%$ sesuai. 


\subsubsection{Hydrant}

Peraturan yang digunakan dalam analisis gap hydrant ini adalah [1] dan [5]. Analisis kondisi hydrant dapat dilihat pada Tabel 5 berikut:

Tabel 5. Hasil Analisis Kondisi Hydrant pada X Mall

\begin{tabular}{|c|c|c|c|c|c|c|c|}
\hline No. & Kondisi Existing & $\sum$ & $\begin{array}{l}\text { Kondisi yang } \\
\text { Diharapkan }\end{array}$ & $\sum$ & Gap & $\begin{array}{c}\text { Persentase } \\
\text { Kesesuaian }\end{array}$ & Rekomendasi \\
\hline \multirow[t]{10}{*}{1} & $\begin{array}{l}\text { Jumlah hydrant } \\
\text { terpasang pada } \\
\text { gedung: }\end{array}$ & & $\begin{array}{l}\text { Jumlah hydrant } \\
\text { yang dibutuhkan: }\end{array}$ & & & & \\
\hline & Lantai SB & 6 & Lantai SB & 10 & -4 & $60 \%$ & Menambah 4 unit alat \\
\hline & Lantai LG & 6 & Lantai LG & 10 & -4 & $60 \%$ & Menambah 4 unit alat \\
\hline & Lantai GF & 6 & Lantai GF & 10 & -4 & $60 \%$ & Menambah 4 unit alat \\
\hline & Lantai FF & 6 & Lantai FF & 10 & -4 & $60 \%$ & Menambah 4 unit alat \\
\hline & Lantai P1 & 8 & Lantai P1 & 10 & -2 & $80 \%$ & Menambah 2 unit alat \\
\hline & Lantai P2 & 8 & Lantai P2 & 1 & +7 & $100 \%$ & - \\
\hline & Lantai 4 & 1 & Lantai 4 & 1 & 0 & $100 \%$ & - \\
\hline & Lantai 5 & 1 & Lantai 5 & 1 & 0 & $100 \%$ & - \\
\hline & Lantai 6 & 1 & Lantai 6 & 1 & 0 & $100 \%$ & - \\
\hline 2 & $\begin{array}{l}\text { Terdapat } 1 \text { titik } \\
\text { hydrant pada } \\
\text { setiap luasan } \\
\text { diatas } \\
1.000 \mathrm{~m}^{2}\end{array}$ & & $\begin{array}{l}\text { Pada setiap luas } \\
\text { lantai } 800 \mathrm{~m}^{2} \\
\text { minimal terdapat } \\
1 \text { titik hydrant }\end{array}$ & & $\begin{array}{l}\text { Partial } \\
\text { Gap }\end{array}$ & $60 \%$ & $\begin{array}{l}\text { Menambah jumlah alat } \\
\text { sesuai dengan yang } \\
\text { dibutuhkan beserta tata } \\
\text { letaknya sehingga pada } \\
\text { setiap luasan } 800 \mathrm{~m}^{2} \\
\text { terdapat } 1 \text { titik hydrant }\end{array}$ \\
\hline 3 & $\begin{array}{l}\text { Panjang slang } \\
30 \mathrm{~m}\end{array}$ & & $\begin{array}{l}\text { Panjang slang } \\
\text { minimal } 30 \mathrm{~m}\end{array}$ & & - & $100 \%$ & $\begin{array}{l}\text { Kondisi sesuai, tetapi } \\
\text { harus dilakukan } \\
\text { pemeliharaan rutin agar } \\
\text { slang tetap berfungsi } \\
\text { dengan baik }\end{array}$ \\
\hline 4 & $\begin{array}{l}\text { Diameter slang } \\
\text { hydrant } 2 \text { inci }\end{array}$ & & $\begin{array}{l}\text { Diameter slang } \\
\text { untuk yang sudah } \\
\text { terlatih diatas } 1,5 \\
\text { inci }\end{array}$ & & - & $100 \%$ & $\begin{array}{l}\text { Kondisi sesuai, tetapi } \\
\text { harus dilakukan pelatihan } \\
\text { agar penghuni gedung } \\
\text { mengetahui cara } \\
\text { penggunaan alat tersebut }\end{array}$ \\
\hline 5 & $\begin{array}{l}\text { Hydrant berwana } \\
\text { merah dengan } \\
\text { tulisan putih }\end{array}$ & & $\begin{array}{l}\text { Hydrant berwana } \\
\text { merah dengan } \\
\text { tulisan putih }\end{array}$ & & - & $100 \%$ & $\begin{array}{l}\text { Kondisi sesuai, tetapi } \\
\text { harus dilakukan sosialisai } \\
\text { agar penghuni gedung } \\
\text { mengenali alat-alat } \\
\text { proteksi aktif gedung }\end{array}$ \\
\hline & $\overline{\text { PERSENTA }}$ & & KESESUAIAN RA & & & $88,0 \%$ & \\
\hline
\end{tabular}

Berdasarkan Tabel 5 dapat diketahui bahwa persentase kesesuaian hydrant yang terpasang pada gedung adalah $88,0 \%$ sesuai. 


\subsubsection{Alat Pemadam Api Ringan (APAR)}

Peraturan yang digunakan dalam analisis gap APAR ini adalah [1]. Analisis kondisi APAR dapat dilihat pada Tabel 6 berikut:

Tabel 6. Hasil Analisis Kondisi APAR pada X Mall

\begin{tabular}{clllllll}
\hline No. & Kondisi Existing & $\sum$ & $\begin{array}{c}\text { Kondisi yang } \\
\text { Diharapkan }\end{array}$ & $\sum$ & Gap & $\begin{array}{c}\text { Persentase } \\
\text { Kesesuaian }\end{array}$ & Rekomendasi \\
\hline 1 & $\begin{array}{l}\text { Jumlah APAR } \\
\text { terpasang pada } \\
\text { gedung: }\end{array}$ & $\begin{array}{l}\text { Jumlah APAR } \\
\text { yang dibutuhkan: }\end{array}$ & & & & \\
\cline { 2 - 8 } & 10 & Lantai SB & 36 & -16 & $28 \%$ & Menambah 16 unit alat \\
\hline Lantai SB & 10 & Lantai LG & 36 & -16 & $28 \%$ & Menambah 16 unit alat \\
\hline Lantai LG & 10 & Lantai GF & 36 & -16 & $28 \%$ & Menambah 16 unit alat \\
\hline Lantai GF & 10 & Lantai FF & 36 & -16 & $28 \%$ & Menambah 16 unit alat \\
\hline Lantai FF & 10 & Lantai P1 & 36 & -16 & $28 \%$ & Menambah 16 unit alat \\
\hline
\end{tabular}

Tabel 6. Hasil Analisis Kondisi APAR pada X Mall (lanjutan)

\begin{tabular}{|c|c|c|c|c|c|c|c|}
\hline No. & Kondisi Existing & $\sum$ & $\begin{array}{l}\text { Kondisi yang } \\
\text { Diharapkan }\end{array}$ & $\sum$ & Gap & $\begin{array}{l}\text { Persentase } \\
\text { Kesesuaian }\end{array}$ & Rekomendasi \\
\hline & Lantai P2 & 15 & Lantai P2 & 3 & +12 & $100 \%$ & - \\
\hline & Lantai 4 & 2 & Lantai 4 & 3 & -1 & $67 \%$ & Menambah 1 unit alat \\
\hline & Lantai 5 & 2 & Lantai 5 & 3 & -1 & $67 \%$ & Menambah 1 unit alat \\
\hline & Lantai 6 & 2 & Lantai 6 & 3 & -1 & $67 \%$ & Menambah 1 unit alat \\
\hline 2 & $\begin{array}{l}\text { Jarak antar APAR } \\
\text { yang terpasang } \\
\text { adalah } 30 \mathrm{~m} \\
\text { sampai } 40 \mathrm{~m}\end{array}$ & & $\begin{array}{l}\text { Jarak anatar } \\
\text { APAR maksimal } \\
15 \mathrm{~m}\end{array}$ & & $\begin{array}{l}\text { Partial } \\
\text { Gap }\end{array}$ & $50 \%$ & $\begin{array}{l}\text { Menambah jumlah alat } \\
\text { sesuai dengan yang } \\
\text { dibutuhkan beserta tata } \\
\text { letaknya sehingga } \\
\text { jarak antar APAR tidak } \\
\text { lebih dari } 15 \mathrm{~m}\end{array}$ \\
\hline 3 & $\begin{array}{l}\text { Terdapat petunjuk } \\
\text { pengoperasian } \\
\text { APAR }\end{array}$ & & $\begin{array}{l}\text { Ada petunjuk } \\
\text { pengoperasian di } \\
\text { bagian depan } \\
\text { APAR }\end{array}$ & & & $100 \%$ & - \\
\hline 4 & $\begin{array}{l}\text { Pemeriksaan } \\
\text { APAR dilakukan } \\
\text { setiap } \quad 3 \\
\text { bulan }\end{array}$ & & $\begin{array}{l}\text { Pemeriksaan } \\
\text { APAR minimal } 2 \\
\text { kali dalam satu } \\
\text { tahun }\end{array}$ & & - & $100 \%$ & - \\
\hline 5 & $\begin{array}{l}\text { APAR } \\
\text { ditempatkan } \\
\text { di dalam box } \\
\text { hydrant atau box } \\
\text { kaca yang mudah } \\
\text { dijangkau }\end{array}$ & & $\begin{array}{l}\text { APAR } \\
\text { ditempatkan di } \\
\text { lokasi yang } \\
\text { sangat jelas dan } \\
\text { sangat mudah } \\
\text { dijangkau saat } \\
\text { kebakaran }\end{array}$ & & - & $100 \%$ & $\begin{array}{l}\text { Kondisi sesuai, tetapi } \\
\text { harus dilakukan } \\
\text { pelatihan agar } \\
\text { penghuni gedung } \\
\text { mengetahui cara } \\
\text { penggunaan APAR }\end{array}$ \\
\hline
\end{tabular}

Berdasarkan Tabel 6 dapat diketahui bahwa persentase kesesuaian APAR yang terpasang pada gedung adalah $80,0 \%$ sesuai. 


\subsection{Sistem Proteksi Pasif}

Peraturan yang digunakan dalam pembahasan sistem proteksi pasif adalah [1] dan [6]. Analisis kondisi sistem proteksi pasif dapat dilihat pada Tabel 7 berikut:

Tabel 7. Hasil Analisis Kondisi Sistem Proteksi Pasif pada X Mall

\begin{tabular}{|c|c|c|c|c|c|}
\hline No. & Kondisi Existing & $\begin{array}{l}\text { Kondisi yang } \\
\text { Diharapkan }\end{array}$ & Gap & $\begin{array}{l}\text { Persentase } \\
\text { Kesesuaian }\end{array}$ & Rekomendasi \\
\hline 1 & $\begin{array}{l}\text { Bahan bangunan utama } \\
\text { yang digunakan adalah } \\
\text { beton bertulang dan bata } \\
\text { merah yang memiliki } \\
\text { ketahan terhadap api } \\
\text { cukup tinggi }\end{array}$ & $\begin{array}{l}\text { Bahan bangunan yang } \\
\text { digunakan harus mampu } \\
\text { menahan penjalaran } \\
\text { kebakaran untuk } \\
\text { membatasi pertumbuhan } \\
\text { asap dan panas serta } \\
\text { terbentuknya gas } \\
\text { beracun }\end{array}$ & - & $100 \%$ & - \\
\hline 2 & $\begin{array}{l}\text { Kondisi konstruksi } \\
\text { bangunan dalam keadaan } \\
\text { baik dan memiliki } \\
\text { stabilitas struktur }\end{array}$ & $\begin{array}{l}\text { Struktur bangunan pada } \\
\text { setiap kelas bangunan } \\
\text { harus memiliki } \\
\text { ketahanan api terhadap } \\
\text { keruntuhan struktur }\end{array}$ & - & $100 \%$ & - \\
\hline 3 & $\begin{array}{l}\text { Tidak terdapat sistem } \\
\text { kompartemenisasi } \\
\text { khusus tahan api }\end{array}$ & $\begin{array}{l}\text { Kompartemensasi dan } \\
\text { dinding pemisah harus } \\
\text { tahan api selama } 180 \\
\text { menit }\end{array}$ & - & $10 \%$ & - \\
\hline 4 & $\begin{array}{l}\text { Tidak terdapat penutup } \\
\text { dan bukaan khusus, } \\
\text { hanya terpasang bukaan } \\
\text { atap biasa yang berfungsi } \\
\text { sebagai jalan keluarnya } \\
\text { asap }\end{array}$ & $\begin{array}{l}\text { Penutup dan bukaan } \\
\text { horizontal dan vertikal } \\
\text { harus dari bahan yang } \\
\text { tidak mudah terbakar }\end{array}$ & $\begin{array}{l}\text { Full } \\
\text { gap }\end{array}$ & $20 \%$ & $\begin{array}{l}\text { Dibuat sistem penutup } \\
\text { dan bukaan tahan api } \\
\text { pada setiap } \\
\text { kompartemensasi } \\
\text { bangunan untuk } \\
\text { mengatasi penyebaran } \\
\text { asap }\end{array}$ \\
\hline \multicolumn{4}{|c|}{ PERSENTASE KESESUAIAN RATA-RATA } & $80,0 \%$ & \\
\hline
\end{tabular}

Berdasarkan Tabel 7 dapat diketahui bahwa persentase kesesuaian sistem proteksi pasif yang terpasang pada gedung adalah $80,0 \%$ sesuai.

\subsection{Sarana Penyelamatan Jiwa}

Sarana penyelamatan jiwa meliputi tangga darurat, pintu keluar, koridor, lampu penerangan, tanda petunjuk arah dan tempat berhimpun yang akan dibandingkan dengan Kepmen PU No. 10/KPTS/2000 [1] dan SNI 03-1746-2000 tentang Tata Cara Perencanaan dan Pemasangan Sarana Jalan ke Luar untuk Penyelamatan Terhadap Bahaya Kebakaran pada Bangunan Gedung [7] dan SNI 03-6574-2001 tentang Tata Cara Perancangan Pencahayaan Darurat, Tanda Arah, dan Sistem Peringatan Bahaya pada Bangunan Gedung [8]. 


\subsubsection{Koridor}

Analisis kondisi koridor pada gedung X Mall dapat dilihat pada Tabel 8 berikut:

Tabel 8. Hasil Analisis Kondisi Koridor pada X Mall

\begin{tabular}{|c|c|c|c|c|c|}
\hline No. & Kondisi Existing & $\begin{array}{l}\text { Kondisi yang } \\
\text { Diharapkan }\end{array}$ & Gap & $\begin{array}{l}\text { Persentase } \\
\text { Kesesuaian }\end{array}$ & Rekomendasi \\
\hline 1 & $\begin{array}{l}\text { Lebar koridor pada } \\
\text { gedung adalah } 2 \mathrm{~m} \\
\text { sampai } 4 \mathrm{~m}\end{array}$ & $\begin{array}{l}\text { Lebar minimum } \\
\text { koridor } 1,8 \mathrm{~m}\end{array}$ & - & $100 \%$ & $\begin{array}{l}\text { Kondisi sesuai, koridor harus } \\
\text { dijaga tetap dapat dilewati } \\
\text { dengan mudah tanpa } \\
\text { terhalang oleh benda-benda } \\
\text { yang mengganggu khususnya } \\
\text { pada gedung ini adalah } \\
\text { barang-barang milik tenants }\end{array}$ \\
\hline 2 & $\begin{array}{l}\text { Koridor pada } \\
\text { gedung merupakan } \\
\text { bangunan } \\
\text { permanen yang } \\
\text { terbuat dari dinding } \\
\text { bata merah dan } \\
\text { lantai beton } \\
\text { bertulang }\end{array}$ & $\begin{array}{l}\text { Koridor merupakan } \\
\text { bangunan yang } \\
\text { permanen }\end{array}$ & - & $100 \%$ & - \\
\hline 3 & $\begin{array}{l}\text { Tinggi koridor pada } \\
\text { gedung adalah } 3 \mathrm{~m} \\
\text { sampai } 4 \mathrm{~m}\end{array}$ & $\begin{array}{l}\text { Tinggi bersih koridor } \\
\text { minimal } 2,3 \mathrm{~m}\end{array}$ & - & $100 \%$ & - \\
\hline \multicolumn{4}{|c|}{ PERSENTASE KESESUAIAN RATA-RATA } & $100,0 \%$ & \\
\hline
\end{tabular}

Berdasarkan Tabel 8 dapat diketahui bahwa persentase kesesuaian koridor yang terpasang pada gedung adalah $100 \%$ sesuai.

\subsubsection{Pencahayaan Darurat}

Analisis kondisi pencahayaan darurat pada gedung X Mall dapat dilihat pada Tabel 9 berikut:

Tabel 9. Hasil Analisis Kondisi Pencahayaan Darurat pada X Mall

\begin{tabular}{|c|c|c|c|c|c|}
\hline No. & Kondisi Existing & $\begin{array}{c}\text { Kondisi yang } \\
\text { Diharapkan }\end{array}$ & Gap & $\begin{array}{l}\text { Persentase } \\
\text { Kesesuaian }\end{array}$ & Rekomendasi \\
\hline 1 & $\begin{array}{l}\text { Lampu darurat bekerja } \\
\text { otomatis apabila listrik } \\
\text { padam dan } \\
\text { memberikan } \\
\text { pencahayaan pada } \\
\text { akses exit seperti } \\
\text { koridor dan tangga } \\
\text { darurat }\end{array}$ & $\begin{array}{l}\text { Lampu darurat } \\
\text { bekerja otomatis dan } \\
\text { dapat memberikan } \\
\text { pencahayaan } \\
\text { pada fasilitas } \\
\text { peralatan proteksi } \\
\text { kebakaran }\end{array}$ & - & $100 \%$ & $\begin{array}{l}\text { Kondisi sesuai, lampu } \\
\text { harus diperiksa dan } \\
\text { dipelihara secara rutin } \\
\text { agar tetap berfungsi } \\
\text { dengan baik }\end{array}$ \\
\hline 2 & $\begin{array}{l}\text { Lampu darurat } \\
\text { mengarahkan pada } \\
\text { jalan menuju keluar } \\
\text { gedung }\end{array}$ & $\begin{array}{l}\text { Lampu darurat } \\
\text { memberikan } \\
\text { petunjuk/rambu } \\
\text { rambu yang cukup } \\
\text { jelas untuk menuju } \\
\text { jalan keluar (exit) dan }\end{array}$ & - & $100 \%$ & $\begin{array}{l}\text { Kondisi sesuai, harus } \\
\text { dilakukan sosialisasi } \\
\text { agar penghuni gedung } \\
\text { mengetahui fungsi } \\
\text { dari lampu darurat }\end{array}$ \\
\hline
\end{tabular}




\begin{tabular}{ll}
\hline \multicolumn{2}{c}{$\begin{array}{l}\text { alur pencapaian } \\
\text { menuju exit }\end{array}$} \\
\hline PERSENTASE KESESUAIAN RATA-RATA & $\mathbf{1 0 0 , 0 \%}$ \\
\hline
\end{tabular}

Berdasarkan Tabel 9 dapat diketahui bahwa persentase kesesuaian pencahayaan darurat yang terpasang pada gedung adalah $100 \%$ sesuai.

\subsubsection{Tanda Petunjuk Arah}

Analisis kondisi tanda petunjuk arah pada gedung X Mall dapat dilihat pada Tabel 10 berikut:

Tabel 10. Hasil Analisis Kondisi Tanda Petunjuk Arah pada X Mall

\begin{tabular}{|c|c|c|c|c|c|}
\hline No. & Kondisi Existing & $\begin{array}{l}\text { Kondisi yang } \\
\text { Diharapkan }\end{array}$ & Gap & $\begin{array}{l}\text { Persentase } \\
\text { Kesesuaian }\end{array}$ & Rekomendasi \\
\hline 1 & $\begin{array}{l}\text { Terpasang tanda } \\
\text { petunjuk arah menuju } \\
\text { jalan keluar }\end{array}$ & $\begin{array}{l}\text { Sarana menuju jalan } \\
\text { keluar harus diberi } \\
\text { tanda arah }\end{array}$ & - & $100 \%$ & $\begin{array}{l}\text { Kondisi sesuai, tanda } \\
\text { harus dipelihara agar } \\
\text { tetap dapat terbaca }\end{array}$ \\
\hline 2 & $\begin{array}{l}\text { Terpasang tanda } \\
\text { petunjuk arah evakuasi } \\
\text { pada setiap koridor dan } \\
\text { terpasang denah jalur } \\
\text { evakuasi pada setiap } \\
\text { lantai }\end{array}$ & $\begin{array}{l}\text { Arah menuju tempat } \\
\text { yang aman harus } \\
\text { diberi tanda arah } \\
\text { dengan tanda arah } \\
\text { yang disetujui, } \\
\text { di lokasi yang mudah } \\
\text { dibaca dari segala } \\
\text { arah jalan }\end{array}$ & - & $100 \%$ & $\begin{array}{l}\text { Kondisi sesuai, harus } \\
\text { dilakukan sosialisasi } \\
\text { agar penghuni gedung } \\
\text { dapat mengerti arti } \\
\text { tanda petunjuk yang } \\
\text { terpasang }\end{array}$ \\
\hline \multirow[t]{2}{*}{3} & $\begin{array}{l}\text { Terpasang tanda } \\
\text { "EXIT" pada jalan } \\
\text { keluar }\end{array}$ & $\begin{array}{l}\text { Tanda arah harus } \\
\text { dengan kata "EXIT" }\end{array}$ & - & $100 \%$ & $\begin{array}{l}\text { Kondisi sesuai, tanda } \\
\text { harus dipelihara agar } \\
\text { tetap dapat terbaca }\end{array}$ \\
\hline & PERSENTASE KE & ESUAIAN RATA-RA & & $100,0 \%$ & \\
\hline
\end{tabular}

Berdasarkan Tabel 10 dapat diketahui bahwa persentase kesesuaian tanda petunjuk arah yang terpasang pada gedung adalah $100 \%$ sesuai.

\subsubsection{Pintu Darurat}

Analisis kondisi pintu darurat pada gedung X Mall dapat dilihat pada Tabel 11 berikut:

Tabel 11. Hasil Analisis Kondisi Pintu Darurat pada X Mall

\begin{tabular}{|c|c|c|c|c|c|}
\hline No. & Kondisi Existing & Kondisi yang Diharapkan & Gap & $\begin{array}{l}\text { Persentase } \\
\text { Kesesuaian }\end{array}$ & Rekomendasi \\
\hline 1 & $\begin{array}{l}\text { Lebar bukaan pintu } \\
110 \mathrm{~cm}\end{array}$ & $\begin{array}{l}\text { Lebar bukaan pintu minimal } \\
80 \mathrm{~cm}\end{array}$ & - & $100 \%$ & $\begin{array}{l}\text { Kondisi sesuai, pintu } \\
\text { harus dijaga dalam } \\
\text { keadaan dapat dibuka } \\
\text { ketika kondisi darurat }\end{array}$ \\
\hline 2 & $\begin{array}{l}\text { Pintu kebakaran } \\
\text { membuka ke arah } \\
\text { tangga darurat yang } \\
\text { menuju tempat } \\
\text { berhimpun }\end{array}$ & $\begin{array}{l}\text { Pintu kebakaran harus } \\
\text { membuka atau berayun ke } \\
\text { arah lintasan jalan ke luar } \\
\text { apabila digunakan untuk } \\
\text { melayani ruangan atau }\end{array}$ & - & $100 \%$ & $\begin{array}{l}\text { Kondisi sesuai, harus } \\
\text { dilakukan sosialisasi } \\
\text { agar penghuni gedung } \\
\text { mengetahui cara } \\
\text { membuka pintu darurat }\end{array}$ \\
\hline
\end{tabular}




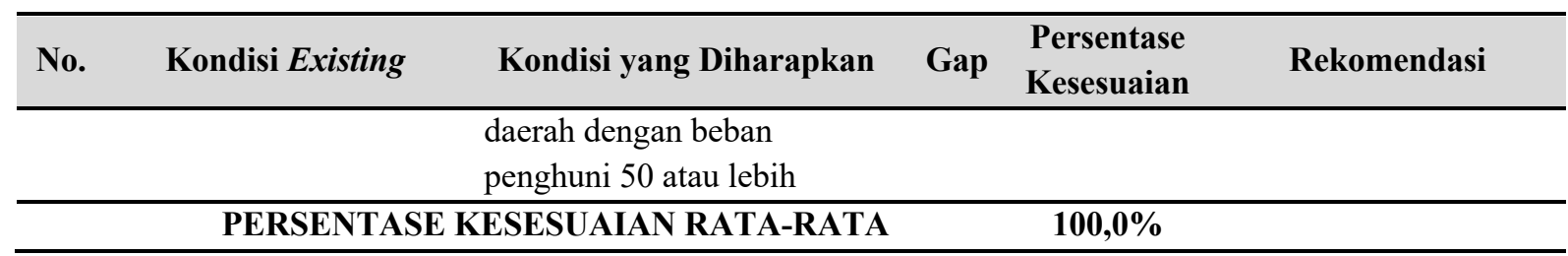

Berdasarkan Tabel 11 dapat diketahui bahwa persentase kesesuaian pintu darurat yang terpasang pada gedung adalah $100 \%$ sesuai.

\subsubsection{Tangga Darurat}

Analisis kondisi tangga darurat pada gedung X Mall dapat dilihat pada Tabel 12 berikut:

Tabel 12. Hasil Analisis Kondisi Tangga Darurat pada X Mall

\begin{tabular}{|c|c|c|c|c|c|}
\hline No. & Kondisi Existing & $\begin{array}{l}\text { Kondisi yang } \\
\text { Diharapkan }\end{array}$ & Gap & $\begin{array}{l}\text { Persentase } \\
\text { Kesesuaian }\end{array}$ & Rekomendasi \\
\hline 1 & $\begin{array}{l}\text { Tangga darurat } \\
\text { terhubung dengan pintu } \\
\text { darurat dan tempat } \\
\text { berhimpun }\end{array}$ & $\begin{array}{l}\text { Tangga menuju } \\
\text { tempat terbuka atau } \\
\text { terhubung dengan } \\
\text { pintu darurat }\end{array}$ & - & $100 \%$ & $\begin{array}{l}\text { Kondisi sesuai, tangga } \\
\text { darurat harus dijaga } \\
\text { agar tetap dapat } \\
\text { digunakan dalam } \\
\text { kondisi darurat dan } \\
\text { dilakukan sosialisasi } \\
\text { agar pengunjung } \\
\text { mengetahui letak } \\
\text { tangga darurat. }\end{array}$ \\
\hline
\end{tabular}

Tabel 12. Hasil Analisis Kondisi Tangga Darurat pada X Mall (lanjutan)

\begin{tabular}{|c|c|c|c|c|c|}
\hline No. & Kondisi Existing & $\begin{array}{l}\text { Kondisi yang } \\
\text { Diharapkan }\end{array}$ & Gap & $\begin{array}{l}\text { Persentase } \\
\text { Kesesuaian }\end{array}$ & Rekomendasi \\
\hline 2 & $\begin{array}{l}\text { Tangga darurat terbuat } \\
\text { dari beton bertulang } \\
\text { dengan ketahanan api } \\
\text { selama } 2 \text { jam }\end{array}$ & $\begin{array}{l}\text { Setiap tangga dalam } \\
\text { bangunan yang } \\
\text { dipersyaratkan harus } \\
\text { dari bahan yang tidak } \\
\text { mudah terbakar }\end{array}$ & - & $100 \%$ & - \\
\hline 3 & $\begin{array}{l}\text { Tangga darurat sama } \\
\text { dengan lebar bordes } \\
\text { sepanjang arah jalan } \\
\text { keluar }\end{array}$ & $\begin{array}{l}\text { Tangga dan bordes } \\
\text { antar tangga harus } \\
\text { sama lebar dengan } \\
\text { tanpa pengurangan } \\
\text { lebar sepanjang arah } \\
\text { lintasan jalan ke luar }\end{array}$ & - & $100 \%$ & - \\
\hline \multirow[t]{2}{*}{4} & $\begin{array}{l}\text { Tangga darurat } \\
\text { dilengkapi dengan } \\
\text { pagar pengaman serta } \\
\text { penahan benda jatuh } \\
\text { pada sisi yang terbuka }\end{array}$ & $\begin{array}{l}\text { Tangga harus } \\
\text { dilengkapi dengan } \\
\text { pagar pengaman } \\
\text { untuk mencegah jatuh } \\
\text { dari sisi yang terbuka }\end{array}$ & - & $100 \%$ & - \\
\hline & \multicolumn{3}{|c|}{ PERSENTASE KESESUAIAN RATA-RATA } & $100,0 \%$ & \\
\hline
\end{tabular}

Berdasarkan Tabel 12 dapat diketahui bahwa persentase kesesuaian tangga darurat yang terpasang pada gedung adalah $100 \%$ sesuai. 


\subsubsection{Tempat Berhimpun}

Analisis kondisi tempat berhimpun pada gedung X Mall dapat dilihat pada Tabel 13 berikut:

Tabel 13. Hasil Analisis Kondisi Pintu Darurat pada X Mall

\begin{tabular}{|c|c|c|c|c|c|}
\hline No. & Kondisi Existing & $\begin{array}{l}\text { Kondisi yang } \\
\text { Diharapkan }\end{array}$ & Gap & $\begin{array}{l}\text { Persentase } \\
\text { Kesesuaian }\end{array}$ & Rekomendasi \\
\hline 1 & $\begin{array}{l}\text { Terdapat dua tempat } \\
\text { berhimpun yang berada } \\
\text { pada sisi timur dan sisi } \\
\text { barat gedung }\end{array}$ & $\begin{array}{l}\text { Terdapat tempat } \\
\text { berhimpun pada bangunan } \\
\text { gedung }\end{array}$ & - & $100 \%$ & $\begin{array}{l}\text { Kondisi Sesuai, pada } \\
\text { tempat berhimpun } \\
\text { tidak boleh } \\
\text { dipergunakan untuk } \\
\text { keperluan lain agar } \\
\text { evakuasi tidak } \\
\text { terganggu }\end{array}$ \\
\hline 2 & $\begin{array}{l}\text { Tempat berhimpun } \\
\text { mudah dicapai karena } \\
\text { terhubung langsung } \\
\text { dengan tangga dan } \\
\text { pintu darurat dari } \\
\text { dalam gedung }\end{array}$ & $\begin{array}{l}\text { Bagian dari sebuah daerah } \\
\text { tempat perlindungan harus } \\
\text { mudah dicapai dari tempat } \\
\text { yang dilayani oleh sarana } \\
\text { jalan ke luar yang mudah } \\
\text { dicapai }\end{array}$ & - & $100 \%$ & - \\
\hline 3 & $\begin{array}{l}\text { Tempat berhimpun } \\
\text { langsung terhubung } \\
\text { dengan jalan umum } \\
\text { tanpa harus kembali } \\
\text { kedalam bangunan }\end{array}$ & $\begin{array}{l}\text { Bagian dari daerah tempat } \\
\text { perlindungan yang } \\
\text { dipersyaratkan harus } \\
\text { mempunyai akses ke suatu } \\
\text { jalan umum melalui exit } \\
\text { atau lift, tanpa kembali ke } \\
\text { dalam tempat di } \\
\text { bangunan, melalui } \\
\text { lintasan daerah tempat } \\
\text { perlindungan }\end{array}$ & - & $100 \%$ & - \\
\hline \multicolumn{4}{|c|}{ PERSENTASE KESESUAIAN RATA-RATA } & $100,0 \%$ & \\
\hline
\end{tabular}

Berdasarkan Tabel 13 dapat diketahui bahwa persentase kesesuaian tempat berhimpun yang dibangun pada gedung adalah $100 \%$ sesuai.

\subsection{Manajemen Keselamatan Kebakaran}

Analisis Manajemen Keselamatan Kebakaran pada gedung X Mall dapat dilihat pada Tabel 14 berikut:

Tabel 14. Hasil Analisis Manajemen Keselmatan Kebakaran yang Diterapkan pada X Mall

\begin{tabular}{|c|c|c|c|c|c|}
\hline No. & Kondisi Existing & $\begin{array}{l}\text { Kondisi yang } \\
\text { Diharapkan }\end{array}$ & Gap & $\begin{array}{l}\text { Persentase } \\
\text { Kesesuaian }\end{array}$ & Rekomendasi \\
\hline 1 & $\begin{array}{l}\text { X Mall memiliki fire } \\
\text { brigade dalam gedung } \\
\text { yang memiliki struktur } \\
\text { organisasi }\end{array}$ & $\begin{array}{l}\text { Terdapat struktur } \\
\text { organisasiManajemen } \\
\text { Keselamatan } \\
\text { Kebakaran Gedung }\end{array}$ & - & $100 \%$ & - \\
\hline 2 & $\begin{array}{l}\text { Petugas security dan } \\
\text { firebrigade bertugas } \\
\text { untuk tindak darurat } \\
\text { kebakaran pada gedung }\end{array}$ & $\begin{array}{l}\text { Keberadaan petugas } \\
\text { untuk tindak darurat } \\
\text { kebakaran }\end{array}$ & - & $100 \%$ & - \\
\hline
\end{tabular}




\begin{tabular}{|c|c|c|c|c|c|}
\hline No. & Kondisi Existing & $\begin{array}{c}\text { Kondisi yang } \\
\text { Diharapkan }\end{array}$ & Gap & $\begin{array}{l}\text { Persentase } \\
\text { Kesesuaian }\end{array}$ & Rekomendasi \\
\hline 3 & $\begin{array}{l}\text { Simulasi kebakaran } \\
\text { tahunan diikuti oleh } \\
\text { setiap perwakilan pekerja }\end{array}$ & $\begin{array}{l}\text { Penyuluhan dan } \\
\text { pelatihan kebakaran } \\
\text { bagi penghuni gedung }\end{array}$ & - & $100 \%$ & $\begin{array}{l}\text { Sebaiknya diadakan simulasi } \\
\text { kebakaran untuk pengunjung } \\
\text { gedung agar masyarakat luas } \\
\text { mengetahui bagaimana cara } \\
\text { tanggap ketika terjadi } \\
\text { kebakaran }\end{array}$ \\
\hline 4 & $\begin{array}{l}\text { Pelatihan penggunaan } \\
\text { APAR dan Fire Blanket } \\
\text { setiap } 3 \text { bulan diikuti oleh } \\
\text { penyewa gedung }\end{array}$ & $\begin{array}{l}\text { Pelatihan penggunaan } \\
\text { APAR yang diadakan } \\
\text { oleh pengelola gedung }\end{array}$ & - & $100 \%$ & - \\
\hline 5 & $\begin{array}{l}\text { Tidak terdapat prasyarat } \\
\text { mengenai barang yang } \\
\text { digunakan tenants }\end{array}$ & $\begin{array}{l}\text { Adanya prasyarat } \\
\text { untuk tenants } \\
\text { (penyewa) agar barang } \\
\text { yang digunakan tidak } \\
\text { memicu api }\end{array}$ & $\begin{array}{l}\text { Full } \\
\text { Gap }\end{array}$ & $0 \%$ & $\begin{array}{l}\text { Dibuat prasyarat untuk tenants } \\
\text { (penyewa) agar barang yang } \\
\text { digunakan tidak memicu api }\end{array}$ \\
\hline
\end{tabular}

\section{KESIMPULAN}

1. Secara umum sistem proteksi yang terpasang pada gedung sudah cukup baik dengan umumnya persentase kesesuaian $\geq 80 \%$.

2. Sistem proteksi pasif yang tidak terdapat pada gedung yaitu penutup atau bukaan khusus. Sebagai upaya mengendalikan asap yag berada pada gedung, terdapat bukaan menerus dari lantai dasar hingga rooftop yaitu skylight yang berfungsi sebagai penerangan alami sekaligus jalan keluarnya asap.

3. Manajemen Keselamatan Kebakaran Gedung yang sudah diterapkan pada X Mall sudah cukup baik dan sesuai dengan yang diharapkan.

\section{DAFTAR PUSTAKA}

[1] Menteri Negara Pekerjaan Umum. (2000). Kepmen PU 10/KPTS/2000, Ketentuan Teknis Pengamanan Terhadap Bahaya Kebakaran pada Bangunan Gedung dan Lingkungan. Jakarta: Kementerian Pekerjaan Umum.

[2] Menteri Tenaga Kerja RI. (1999). KepMenNaKer No. 186 Tahun 1999, Unit Penanggulangan Kebakaran Ditempat Kerja. Jakarta: Kementerian Tenaga Kerja.

[3] Badan Standardisasi Nasional. (2000). SNI 03-3985-2000, Tata Cara Perencanaan, Pemasangan, dan Pengujian Sistem Deteksi dan Alarm Kebakaran untuk Pencegahan Bahaya Kebakaran Pada Gedung. Jakarta: Badan Standardisasi Nasional.

[4] Badan Standardisasi Nasional. (2000). SNI 03-3989-2000, Tata Cara Perencanaan dan Pemasangan Sistem Sprinkler Otomatik untuk Pencegahan Bahaya Kebakaran pada Bangunan Gedung. Jakarta: Badan Standardisasi Nasional.

[5] Badan Standardisasi Nasional. (2000). SNI 03-1745-2000, Tata Cara Perencanaan dan Pemasangan Sistem Pipa Tegak dan Slang untuk Pencegahan Bahaya Kebakaran pada Bangunan Rumah Gedung. Jakarta: Badan Standardisasi Nasional.

[6] Badan Standardisasi Nasional. (2000). SNI 03-1736-2000, Tata Cara Perencanaan Sistem Proteksi Pasif untuk Pencegahan Bahaya Kebakaran pada Bangunan Rumah dan Gedung. Jakarta: Badan Standardisasi Nasional. 
[7] Badan Standardisasi Nasional. (2000). SNI 03-1746-2000, Tata Cara Perencanaan dan Pemasangan Sarana Jalan Keluar untuk Penyelamatan Terhadap Bahaya Kebakaran pada Bangunan Gedung. Jakarta: Badan Standardisasi Nasional.

[8] Badan Standardisasi Nasional. (2001). SNI 03-6574-2001, Tata Cara Perancangan Pencahayaan Darurat, Tanda Arah, dan Sistem Peringatan Bahaya pada Bangunan Gedung. Jakarta: Badan Standardisasi Nasional.

[9] Hadi, M. S., Widjasena, B., \& Suroto. (2015). Analisis Struktur Bangunan yang Ditinjau dari Tangga Darurat pada Pusat Perbelanjaan Mesra Indah Mall Samarinda. Jurnal Kesehatan Masyarakat, 3(2), 177.

[10] Ornam, K. (2011). Kajian Tentang Penerapan Sistem Keselamatan Jiwa Terhadap Bahaya Kebakaran pada Perancangan Pusat Perbelanjaan Mal Madongan Kendari. Unity Journal Arsitektur, 1(2), 93. 
Katarina Rini Ratnayanti, Nur Laeli Hajati, Mutiara Indah Rizki Utama

Jurnal Rekayasa Hijau - 16 